\title{
$\&$ Screening for spine injury in abusive head trauma
}

\author{
Cormac 0. Maher, MD \\ Department of Neurosurgery, University of Michigan, Ann Arbor, Michigan
}

\section{$\mathrm{T}$} HE potential importance of cervical spine (c-spine) injury in abused children has been recognized since the initial description of the "whiplash shaken infant syndrome" by John Caffey in 1974. ${ }^{1}$ Despite this long association, the optimal screening protocol for spine injury in children with abusive head trauma (AHT) has not been settled. In the accompanying article, Dr. Oh and colleagues examine the utility of c-spine MRI (cMRI) in these patients. ${ }^{11}$ At their busy pediatric trauma center, a policy was instituted in 2012 that required all patients with a suspicion of AHT to have cMRI if a brain MRI study was ordered. With their very large clinical volume of AHT as well as their rigorous protocol-driven practice and prospective record keeping, these investigators have made a valuable contribution to our knowledge on this controversial topic.

Using their prior practice of less frequent cMRI screening as a historical comparison, Dr. Oh and colleagues found, not surprisingly, that a policy of more frequent screening for subclinical c-spine injury led to more frequent detection of these injuries. How useful is this higher rate of c-spine injury detection? Undoubtedly, given a large enough sample, there will be individual patients for whom cMRI made a clinical difference-but these cases appear to be very rare. Dr. Oh and colleagues found that 28 of 91 patients undergoing cMRI had an abnormal finding. For most of these patients, however, these abnormalities were soft-tissue or ligamentous injuries of unclear clinical significance. No patients with detection of ligamentous injury on cMRI alone developed instability. The single patient who required surgical treatment had a cervical injury that was also detected on radiographs and/or CT. It is possible to argue that no case of clinically important cervical injury was detected on cMRI alone in this very large series.

When the detection of clinically important findings is expected to be rare, where do we draw the line when screening for injury? On the basis of this article, the true rate of clinically important but otherwise undetected cervical injury that could be diagnosed with the addition of cMRI cannot be determined-except to say that it must be a very uncommon event. This is supported by previous studies without cMRI screening that report a very low incidence of spinal injury associated with pediatric head trauma including AHT. ${ }^{9,12}$ Based on prior reports, we may conclude that the rate of any detectable injury on cMRI in patients with AHT is at least 33\%, but that the rate of clinically relevant c-spine injury is much lower. ${ }^{13}$ These rates are confirmed by the data presented by Dr. Oh and colleagues. Cervical spine injury is probably much more common in the most severe and fatal subset of AHT. ${ }^{4}$

The practice of cMRI screening in patients with AHT currently varies widely across institutions. ${ }^{5}$ The American College of Radiology (ACR) has recommended cMRI when craniocervical junction or c-spine injury is suspected on the basis of the clinical examination or abnormal results on other imaging modalities..$^{13}$ The ACR guidelines also suggest considering cMRI if a brain MRI study is ordered, reflecting the hospital policy instituted by Dr. Oh and colleagues in 2012. Similarly, the American Academy of Pediatrics (AAP) has presented a policy statement that endorses ordering cMRI if a c-spine injury is suspected..$^{10}$ In patients without a suspicion of spine injury, the AAP policy statement acknowledges that cMRI may be considered in some cases to assist with the diagnosis of AHT when the mechanism of injury is not clear.

The legal implications of medical decisions cannot be ignored when caring for patients with AHT. In these cases, caregivers have a societal role in correctly establishing an injury mechanism and potentially removing an abuser from contact with children in the future. Failure to recognize inflicted injury exposes children to a substantial risk of reinjury or death. ${ }^{7}$ The findings on cMRI may assist with sorting out the sometimes complicated legal issues in these cases. ${ }^{2,3}$ The use of cMRI abnormalities as discrimi- 
nators between accidental and inflicted injury remains an area of active research..$^{2,3,8} \mathrm{cMRI}$ abnormalities were not included in the recent prediction rule for diagnosing AHT supported by the Pediatric Brain Injury Research Network. ${ }^{6}$ Cervical injury may play a more important role in excluding nontraumatic causes for imaging findings in suspected abuse. ${ }^{2,3}$ In addition to its potential use for assisting with determining injury causation, documenting the extent of injuries may also have important legal implications in some cases.

In their comprehensive report of a very large series of patients with AHT, Dr. Oh and colleagues have provided some much-needed data that will assist caregivers with these decisions. Hopefully, ongoing efforts will continue to clarify the many questions that remain. Until then, caregivers will need to weigh these issues carefully, taking into account the relatively high pretest probability of a "positive" result and the much lower probability of detecting an injury requiring surgery or any treatment, as well as the separate but vitally important legal consequences of these decisions.

https://thejns.org/doi/abs/10.3171/2017.3.PEDS1775

\section{References}

1. Caffey J: The whiplash shaken infant syndrome: manual shaking by the extremities with whiplash-induced intracranial and intraocular bleedings, linked with residual permanent brain damage and mental retardation. Pediatrics 54:396403, 1974

2. Choudhary AK, Bradford RK, Dias MS, Moore GJ, Boal DKB: Spinal subdural hemorrhage in abusive head trauma: a retrospective study. Radiology 262:216-223, 2012

3. Choudhary AK, Ishak R, Zacharia TT, Dias MS: Imaging of spinal injury in abusive head trauma: a retrospective study. Pediatr Radiol 44:1130-1140, 2014

4. Feldman KW, Weinberger E, Millstein JM, Fligner CL: Cervical spine MRI in abused infants. Child Abuse Negl 21:199-205, 1997

5. Henry MK, Zonfrillo MR, French B, Song L, Feudtner C, Wood JN: Hospital variation in cervical spine imaging of young children with traumatic brain injury. Acad Pediatr 16:684-691, 2016

6. Hymel KP, Armijo-Garcia V, Foster R, Frazier TN, Stoiko M, Christie LM, et al: Validation of a clinical prediction rule for pediatric abusive head trauma. Pediatrics 134:e1537e1544, 2014

7. Jenny C, Hymel KP, Ritzen A, Reinert SE, Hay TC: Analysis of missed cases of abusive head trauma. JAMA 282:621629, 1999 (Erratum in JAMA 282:29, 1999)

8. Kadom N, Khademian Z, Vezina G, Shalaby-Rana E, Rice
A, Hinds T: Usefulness of MRI detection of cervical spine and brain injuries in the evaluation of abusive head trauma. Pediatr Radiol 44:839-848, 2014

9. Kemp AM, Joshi AH, Mann M, Tempest V, Liu A, Holden $\mathrm{S}$, et al: What are the clinical are radiological characteristics of spinal injuries from physical abuse: a systematic review. Arch Dis Child 95:355-360, 2010

10. Kleinman PK, Di Pietro MA, Brody AS, Cassady CI, Wyly JB, Applegate KE, et al: Diagnostic imaging of child abuse. Pediatrics 123:1430-1435, 2009

11. Oh A, Sawvel M, Heaner D, Bhatia A, Reisner A, Tubbs RS, et al: Changes in use of cervical spine magnetic resonance imaging for pediatric patients with nonaccidental trauma. J Neurosurg Pediatr [epub ahead of print June 30, 2017. DOI: 10.3171/2017.2.PEDS16644]

12. Polk-Williams A, Carr BG, Blinman TA, Masiakos PT, Wiebe DJ, Nance ML: Cervical spine injury in young children: a National Trauma Data Bank review. J Pediatr Surg 43:1718-1721, 2008

13. Ryan ME, Palasis S, Saigal G, Singer AD, Karmazyn B, Dempsey ME, et al: ACR appropriateness criteria head trauma-child. J Am Coll Radiol 11:939-947, 2014

\section{Disclosures}

The author reports no conflict of interest.

\section{Response}

\section{Joshua J. Chern, MD, PhD}

Neurosurgery, Children's Healthcare of Atlanta, Georgia

I sincerely thank Dr. Maher for his insights and comments. Dr. Maher raised the important question of where do we draw the line on using a screening test when the expected event is rare (in this case, cervical injury that requires surgery or predisposes the child to delayed instability). In other words, even with a sensitive and specific diagnostic test, one has to recognize that the low prevalence of the disease will limit the positive predictive value (disease is present when the test is positive). For example, with a diagnostic test characteristic of $90 \%$ sensitive and $99 \%$ specific, the positive predictive value is $47 \%$ if the prevalence of the disease is $1 \%$, and $8.3 \%$ if the prevalence is $0.1 \%$. Despite the fact that many resources are now being devoted to improve diagnostic accuracy in all aspects of medicine, it is a reality that a more sensitive test does not make a rare condition common. 